\title{
To be or not to be your son's father/mother
}

\section{A cognitive-pragmatic perspective on terms of address in Najdi and Tunisian Arabic}

\author{
Sami Ben Salamh, Zouheir Maalej and Mohammed Alghbban \\ King Saud University, Kingdom of Saudi Arabia
}

The current article offers a comparative account of the address system of two dialects of Arabic, Najdi and Tunisian Arabic. Capitalizing on the theory of Idealized Cognitive Model, the article defends the view that the two systems display Idealized models, which are central to the system, and non-Idealized models, which are peripheral to it. Najdi Arabic includes Idealized terms such as first names, teknonyms, and kinship terms while non-Idealized models include a battery of terms of address. Tunisian Arabic Idealized models hinge on Si/ Lalla + first names, first names, and kinship terms while non-Idealized models make use of endeared first names, kinship terms, and diminished kinship terms. The two systems are shown to differ at the level of types of encounter (including formality, closeness, and deference), availability of address options, social HORIZONTALITY-VERTICALITY, and use of metaphor and metonymy.

Keywords: Idealized, non-Idealized, teknonym, Si/Lalla+first name, HORIZONTALITY, VERTICALITY, metaphor, metonymy

\section{Introduction}

Terms of address constitute a complex system of social hierarchy (Brown and Gilman 1960), cultural values (Clyne 2009), and interpersonal communication (Martiny 1996). Owing to their face-to-face nature, they are integral to speech acts, enabling their users to define themselves in relation to their interactants according to certain accepted socio-cultural and pragmatic rules of behavior. Terms of address are used to negotiate the best possible way of addressing potential interactants. An inappropriate selection of term of address for a given interlocutor might be felt to invade her privacy or even threaten her face. Acquiring them takes place within 
the family and the surrounding environment, where children learn how to appropriately demarcate themselves vis-à-vis the others in their society.

The address systems in Najdi Arabic and Tunisian Arabic are mostly kinship-based (Maalej 2010; El Guindi and Al Othman 2013) even with strangers, who are addressed metaphorically through a kinship term. As Barakat $(1993,23)$ puts it, "the family is the basic unit of social organization and production in traditional and contemporary Arab society, and it remains a relatively cohesive institution at the center of social and economic activities. It is patriarchal; pyramidally hierarchical, particularly with respect to sex and age; and extended." Accordingly, it is plausible that an investigation of terms of address in the Arabic tradition should study them in relation to the kinship system. Jones $(2004,214)$ shows that "the analysis of kin terms seems to illuminate a different corner of conceptual structure, one grounded not in physical but social cognition."

Although the article compares two address systems, it mainly overly focuses on two Idealized, prototypical terms of address, namely, the teknonym in Najdi Arabic and the Si/Lalla+first name in Tunisian Arabic. A teknonym is a term of address whose components are a kinship term, abu/umm (father of .../mother of ...) + eldest son's first name as in abu Mhammed (father of Mohammed) and umm Mhammed (mother of Mohammed). Though infrequent, the second part of the teknonym may be occupied by the name of the eldest daughter as in abu Hala (the father of Hala). For instance, the famous Saudi singer, Mohamed Abdo, is addressed as abu Nura (Nura's father) to the extent that this teknonym has become a metonym for his own songs. It is not infrequent to hear Saudis ask a friend driving to šaRRel $a b u$ Nura (which means "let one of abu Nura's songs play"). On the other hand, $S i$ in Tunisian Arabic is a short form for Sidi (my master), which most probably originated in serfdom, a system similar to feudalism in medieval Europe. But these feudal-based uses lost the connotation of subordination, and started assuming a dimension of honorification (i.e. respect and deference) to one's elders and the elderly. The Si/Lalla + first name may be used by any young man/lady to address an older man/woman within and outside the family circle.

The objective of the article having been established, a few words about data collection for the article are useful. The dataset used as a source of information for terms of address in Najdi Arabic comes primarily from Bin Towairesh (2012), who collected his data through a rich repertoire of data collection procedures such as questionnaires, focus groups, field observation, interviews, a local Saudi TV show, Internet discussion forums, and newspaper articles. As a native speaker of Najdi Arabic, the first author has also contributed to data collection, complementation, and rectification through consultation with other natives of Najdi Arabic. As for the data on Tunisian Arabic, it is based on Maalej (2010), in particular Table 1 and 
Table 2. Being a native speaker of Tunisian Arabic, the second author brought slight modifications and updates to these tables for the current article after consulting fellow Tunisians. Although both datasets have not been collected for the purpose of the current article, they are being used in an original fashion to compare and contrast terms of address in Najdi Arabic and Tunisian Arabic. In particular, this originality consists in showing the prevalence of the teknonym in Najdi Arabic and its inexistence in Tunisian Arabic, and the prevalence of Si/Lalla + first name in Tunisian Arabic and its inexistence in Najdi Arabic.

The outline of this article is as follows. The first section spells out the Idealized Cognitive Models (ICM) theory of categorization as a theoretical framework. The second section offers an overview of terms of address. The third section deals with the address system in Najdi Arabic while the fourth one presents the address system in Tunisian Arabic. The last section is devoted to a discussion of various practical issues related to culture and society.

\section{The theory of idealized cognitive models}

Lakoff $(1987,8)$ characterizes the human capacity to categorize as "essentially a matter of both human experience and imagination - of perception, motor activity, and culture on the one hand, and of metaphor, metonymy, and mental imagery on the other." Up to the 1960s, the theory of categorization was dominated by rationalists, who believed that "membership in a category depends on the unambiguous possession or non-possession of some criterial properties. Such properties must be both necessary and sufficient in order to determine membership in a category" (Givón 1989, 36).

The real challenge to the classical theory of categorization has come from Rosch's (1978) prototype-based theory. Rosch offered two dimensions for categorization: basicness or centrality and prototypicality. Basicness is the fact that there are basic-level categories, which spread upwards to a superordinate level and downwards to further subordinate categories. For example, chair is more basic and representative of the superordinate category furniture than, say, electric chair, which is a subordinate category. Prototypicality means that the boundaries between categories are not clear-cut. Pertaining to a category is not a function of possessing all attributes of that category, but a function of how much a category shares with the members of the category. Rosch $(1978,37)$ captures prototypicality as follows: "Prototypes appear to be just those members of a category that most reflect the redundancy structure of the category as a whole." For instance, chair is more prototypical than rocking chair and electric chair as a representative of furniture. 
Inspired by Rosch's groundwork, Lakoff offers a reworking of prototype theory in terms of what he calls Idealized Cognitive Models (ICMs). As defined by Lakoff $(1987,68)$, an ICM uses four structuring principles:

\section{i. Propositional structure, as in Fillmore's frames}

ii. Image-schematic structure, as in Langacker's cognitive grammar

iii. Metaphorical mappings, as described by Lakoff and Johnson

iv. Metonymic mappings, as described by Lakoff and Johnson

For Lakoff (1987, 341), cognitive models are not a direct reflection of external reality for two reasons: (i) "they are understood in terms of embodiment, not in terms of direct connection to the external world," and (ii) "they include imaginative aspects of cognition such as metaphor and metonymy." The theory of ICMs is not, therefore, an objectivist theory but a cognitive theory for two reasons. First, "the models themselves are both idealized and cognitive. They do not characterize the world as it is." Second, "the ICMs are not matched to the world itself, but rather to understandings of experience" (Lakoff 1982,172). Thus, it is not infrequent to find "ICMs that are inconsistent with each other" (Lakoff 1982, 172). Moreover, ICMs are open-ended by allowing sub-models to occur.

Lakoff $(1987,70)$ accounts for prototype effects by claiming that "an idealized cognitive model may fit one's understanding of the world either perfectly, very well, pretty well, somewhat well, pretty badly, or not at all." The fit would be typical if the models in the world overlap perfectly with people's ICMs. In this sense, ICMs correspond roughly to Rosch's typical examples or prototypes of a given category, with non-prototypical examples as non-idealized cognitive models. Their role is "to centralize, marginalize, or mark as exceptional" (Edwards 1997, 235) each instance of categorization. The power of the theory of ICMs, thus, lies in the idealized nature of ICMs, which presupposes the existence of non-idealized members.

Lakoff $(1982,164)$ explains that in ICMs "the idealizations involve oversimplifications, and often, metaphorical understandings and theories of reality - both expert theories and what anthropologists have referred to as folk theories." For that, "ICMs are not part of an objectivist semantics" (Lakoff 1982, 169), the reason being that examples that do not fit a given ICM are not considered embarrassing counterexamples to be gotten rid of as is the case with traditional theories of categorization. The ICMs seem to be what individuals in the same culture share, including folk theories of meaning and reality. For instance, most Arabs adopt the Gregorian calendar as an Idealized cognitive model of time management to interact with one another and with the rest of the world. However, for Muslim festivities they follow Prophet Mohammed's Hijri (emigration from Makkah to Medina) calendar as a non-Idealized model. As an exception, Saudi Arabia uses the Hijri calendar as an 
Idealized model and the Gregorian one as a non-Idealized model. Lakoff (1982, 165) makes it clear that "the theory of ICMs depends upon keeping one's idealized cognitive models separate from one's knowledge about and understanding of the world." This theory will be applied in detail to the term of address in Najdi Arabic and Tunisian Arabic in Sections 3 and 4, respectively.

Apart from abiding by Lakoff's organizing principles mentioned above, ICMs are Idealized in the sense that they "describe a kind of prototype effect - an asymmetry in a category, where one member or subcategory is taken to be somehow more basic than the other (or others)" (Lakoff 1987, 60). Therefore, not only is there no contradiction between ICMs and prototypes, but also that if speakers, for instance, were asked about the system of address they would single out the Idealized form, i.e., the form which they think is more evocative and representative of the whole system. A consequence of idealization is that an Idealized model does not exclude non-idealized cases within the system of address as a whole. If a term of address is more representative of the system, it is more frequently used than the less representative non-idealized cases. It is common knowledge that the teknonym is a more central term of address in the Middle Eastern countries, including Iraq, Syria, Jordan, Palestine, Yemen and most Gulf Cooperation Countries as will be attested in the review of the literature in Section 2 below. Non-teknonym countries include North African countries such as Sudan, Libya, Tunisia, Algeria, and Morocco. Before dealing with terms of address in Najdi Arabic and Tunisian Arabic, Section 2 offers an overview of terms of address in the literature.

\section{Overview of terms of address}

Terms of address show how social relationships within a given culture are regulated (Fasold 1990; Holmes 1992). They have been the focus of interest in disciplines such as sociolinguistics (Trudgill 1983; Wardhaugh 1986; Fasold 1990; Holmes 1992; Romaine 1994; Bin Towairesh 2012), pragmatics (Levinson 1983), socio-pragmatics (Martiny 1996), and cognitive-pragmatics (Marmaridou 2000; Maalej 2010). Within sociolinguistics, terms of address have been investigated in the context of language change (Fang and Heng 1983; Scotton and Wanjin 1983; Scotton and Wanjin 1984; Zhucheng 1991; Wong 2005; Peipei 2007).

In Western contexts, terms of address are found to be motivated by power and solidarity (Brown and Gilman 1960), politeness (Brown and Levinson 1987), deference (Trudgill 1983; Thomas 1995), and inequality-unfamiliarity and equality-familiarity (Wardhaugh 1986). Brown and Gilman's (1960) treatment of pronouns of address was very influential, almost privileging pronouns as terms of 
address owing to the existence of the T/V distinction in European languages such as French, German, Italian, and Spanish. For Brown and Gilman (1960, 255), power is motivated by many factors such as "physical strength, wealth, age, sex, institutional role in the church, the state, the army, or within the family." They $(1960,255)$ argue that the real experience of power begins at the family level, with parents as "emperor figures." On the other hand, solidarity resides in "like-mindedness or similar behavior dispositions" (Brown and Gilman 1960, 258).

Subsequent research to Brown and Gilman (1960) shows important departures from the power-solidarity dyad. Terms of address are treated along the variables of sex, age, and social status. Kramer $(1975,198)$, for instance, finds "the sex of the speaker and sex of the addressee" to be "influential in determining appropriate term of address in the United States." Bratt Paulston $(1976,364)$ attributes the change in pronominal address in Sweden to "the historical development of the language and by political ideology." Studying terms of address in German and Swedish, Clyne et al. $(2006,314)$ note that such terms are marked by social distance, whereby German seems to keep two degrees of social distance: A low one associated with $\mathrm{T}$ and a high one associated with $\mathrm{V}$. In contrast, Swedish seems to use $\mathrm{T}$ as an unmarked term of address together with the first name, and reserves $\mathrm{V}$ for very restricted uses in "service encounters," whereby young people address the elderly with V (Clyne 2009, 398). Focusing on terms of address in Russian and Estonian, Pajusalu et al. $(2010,96)$ find that Russians use V as a function of age and deference while Estonians use $\mathrm{T}$ even with older people. Clearly, the motivations for terms of address seem to be shifting away from power to more solidarity and deference.

In non-Western contexts, studies take another direction in line with the cultural values of the languages investigated. Apart from the age and kinship factors, Kasanga $(2009,107)$ invokes "African-ness, i.e., whether or not the addressee is African or perceived as such." Studying the terms of address used by Yoruba women with their husbands, Salami $(2004,67)$ shows that such uses occur in a social context of "dependence and dominance," with husbands addressed through a teknonym, a pet name, but rarely a first name. If a first name is ever used, it is reserved for privacy contexts but not used in public, especially not in the presence of the husband's family members. If a wife is younger than her husband, she must show deference to him in public (Salami 2004, 68). In contrast, Yoon (2004, 191-92) finds that the most common terms of address in Korean are kinship terms and job titles, and that whether they use the one or the other "Korean speakers are in effect forced to make a choice between the two levels (plain and polite), whenever they want to use nouns that refer to human beings." Polite forms are known as honorifics, which employ some features of social hierarchy or VERTICALITY and ASYMMETRY in the Asian context. Such honorification is often a function of age: "From the Korean perspective it is quite hard to say anything without an idea about the age of one's 
interlocutors, since verbal and behavioural norms are differentiated mainly on the basis of age and age difference" (Yoon 2004, 206).

Studies on terms of address in the Arab world are not as prolific as their Western counterparts. Googling them, we were unable to find studies in English on Algeria, Libya, Sudan, Mauritania, Yemen, Syria, UAE, Qatar, Oman, and Bahrain. Most studies consulted focus mainly on four recurrent term of address, namely kinship terms (Farghal and Shakir 1994; Maalej 2010), first names (Potter 1995; Maalej 2010), teknonyms (Masliyah 1998; Farghal and Shakir 1994), and metaphorical uses of kinship terms (Yassin 1977; Farghal and Shakir 1994; Al-Khatib 2003; Maalej 2010). Terms of address are variously used across the Arab world. For instance, Potter's $(1995,220)$ claim that "the use of first name at all times is a rule rather than the exception in the various dialects of Arabic" is only partly accurate. Neither is it the case that "teknonyms are actually found throughout the Arab world" (Bin Towairesh 2012, 46). In general, age and social status seem to be more influential than sex in determining the appropriate terms of address (Yassin 1977; Parkinson 1985; Farghal and Shakir 1994; Al-Khatib 2003; Maalej 2010; Bin Towairesh 2012).

Two important points about metaphor and honorification need to be highlighted. Farghal and Shakir $(1994,246)$ point out that metaphorical kinship terms are not only used by strangers but also by a mother to her son or daughter, attributing motherhood to her children as in 'a3ti-ni may yammah (Give me water, Mother). Such a marked use of kinship terms in Jordanian Arabic corresponds, in Braun (1988) terminology, to "address inversion," and is used affectionately by a mother to a child or youth along with the more unmarked, yabni (my son) and yabinti (my daughter). Al-Khatib $(2003,11)$ notes that addressing or calling one's wife by her first name in public in Jordan shows how much she is cherished and respected. However, calling her with a teknonym distances the husband from his wife in public. On the other hand, Arabaa $(1985,48)$ shows that the use of formal terms of address by the lower class in Egypt counters Brown and Gilman's (1960) claim that terms of address are moving from power to solidarity. Arabaa (1985, 653) also notes that one of the most important findings across sex, class, and age is that "respect for elders is a value which cancels out respect for other types of social superiors."

Of all the dialects of Arabic in the literature, Iraqi Arabic seems to use the teknonym more productively. Masliyah $(1998,114)$ shows that "the use of $a b u$ and umm has become common and part of everyday speech of the Iraqis." Apart from being used as terms of address, teknonyms are also used as terms of reference to conceptualize places ( $a b u$ Greb: notorious central prison in Baghdad), animals ( $a b u$ $z$-zummer: a small fish with a long moustache), professions (Abu l-kabab: the kebab vendor, umm il-xubuz: the (female) bread vendor), prices and values (abul-xamsa: a five-dinar bill), diseases (abu n-nigges: "the thing that itches," which is a malignant 
disease like leprosy), ownership (abu l-bet/umm il-bet: the owner of the house or the one who lives in the house), and socially undesirable traits to ridicule people (umm/Abu d-dagga: the one who has an apparent dot or a mark on his body), and umm il-abaya (the woman with the long garment) (Masliyah 1998, 121).

Before tackling Najdi Arabic address system and since the teknonym is one of the fundamental differences in the address system of Najdi Arabic and Tunisian Arabic, the rest of this section will be devoted to teknonyms. Historically, teknonyms may be assumed to have their roots in the Middle East Arab sub-culture, whereby adopting the name of a real or potential son was motivated, among other things, by practical needs for sons to till the land, take the sheep to the pasture to graze, and increase the family income. The Arab individual can be said to cultivate a form of essentiality of the community for the survival of the family as an economic institution. As a result, "indebtedness to family in Arab societies" (Feghali 1997, $352)$ is still a lived reality. Parkinson $(1985,110)$ explains that teknonyms owe their popularity in the Arab culture to "the great value ascribed to the act of producing sons." As a support for Parkinson's argument, Najdi Arabs may change the abu + first name of first female offspring into the abu + first name of newly born male offspring. Thus, teknonyms turn the natural fact of having a son from a biogenetic factor into a socio-cultural and pragmatic factor, something to be boastful and proud about.

In Najdi Arabic, the teknonym is a kinship-based term of address used by males and, to a lesser degree, by females. However, it should be noted that the raison-d'être of the teknonym may not only be progeny, i.e. the fact that a male or female has given birth to a child in order to hold his or her name. Some young males may be assigned a teknonym after their father's name, which they may keep or drop subsequently. For instance, if the father is named Nasser, the son may be addressed by his own father' name as abu Nasser. Motivations for using a teknonym with young sons may include encouraging them to be proud of their fathers and to incite them to act like adults. It is the norm in Najdi Arabic that even with non-acquaintances a teknonym is used by asking the addressee on a first encounter about his elder son's name (weš esm elwalad? What's your son's name?). Once the latter is given, the speaker starts initiating a teknonym for the hearer in face-to-face interaction.

Teknonyms may contribute to creating a shortlist of terms of address for their users. Suppose one knows ten people holding different names, therefore one would know ten different names. However, in the Najdi context, we can imagine three of these to have a son named Abdullah, another three having a son named Mhammed, and the other four a son named Fahad. These ten cases reduce the list to three teknonyms: abu Abdullah, abu Mhammed, and abu Fahad. Indeed, since most of the Najdi people tend to name their male offspring Abdullah, Mhammed, Fahad, 
Nasser, Saad, etc., many of them in turn become known as abu Abdullah, abu Mhammed, abu Fahad, abu Nasser, abu Saad, etc. This may result in relatives and friends holding similar teknonyms, which may need disambiguation in everyday interpersonal interaction, and may occasion through time amnesia of the real first name of kin, relatives, and friends.

\section{Najdi Arabic address system}

Najd means "highland," which surrounds Riyadh, the capital city of Saudi Arabia. Najdi Arabic is a sub-dialect spoken in the central region of Saudi Arabia. It is one of the five major Saudi sub-dialects, the others being Hijazi (in the West), Shargi (in the East), Shemali (in the North), and Janobi (in the South). These sub-dialects show distinctive features on various linguistic levels. Unlike other sub-dialects, which show affinities with dialects across the borders with Jordan, Yemen, Iraq, and Kuwait, Najdi Arabic has been able to preserve its features owing to the fact that it has no borders with other countries and no seaside.

Table 1 below spells out the address system in Najdi Arabic across types of encounter, gender, and idealized and non-idealized cases. ${ }^{1}$

As a category, a term of address is seen in this article to be represented by Idealized and non-Idealized forms depending on the type of encounter, status, and gender. The subordinate, non-Idealized forms are presupposed by the basic, prototypical Idealized ones. For instance, the use of the teknonym by the young to address the elderly is an Idealized form, presupposing non-Idealized forms such as the kinship term used with relatives and the metaphorical kinship term with strangers. However, the Idealized form in the encounter between a Najdi person and a domestic worker across gender, does not presuppose a non-Idealized one as is clearly represented by the empty slots in Table 1. It should be noted that the list of encounters may not be exhaustive of all the possible face-to-face interactions in the life of Najdi people, and that the symmetrical encounters of Najdi-person to professional and Najdi person to domestic worker are not mentioned because a professional and a domestic worker addressing a Najdi person are expatriates not Najdi people.

Table 1 may convey the impression that first names and kinship terms are more frequent in use, which should not be taken at face value. There are two types of frequency: (i) the visible one in the table, which may be repeated in each encounter, and (ii) the actual use of terms of address in everyday interactions. The table induces

1. The following abbreviations are used throughout the article: DIM (diminutive), END (endearment), FEM (feminine), GEN (gender), MASC (masculine), META (metaphorical), poss (possessive). 


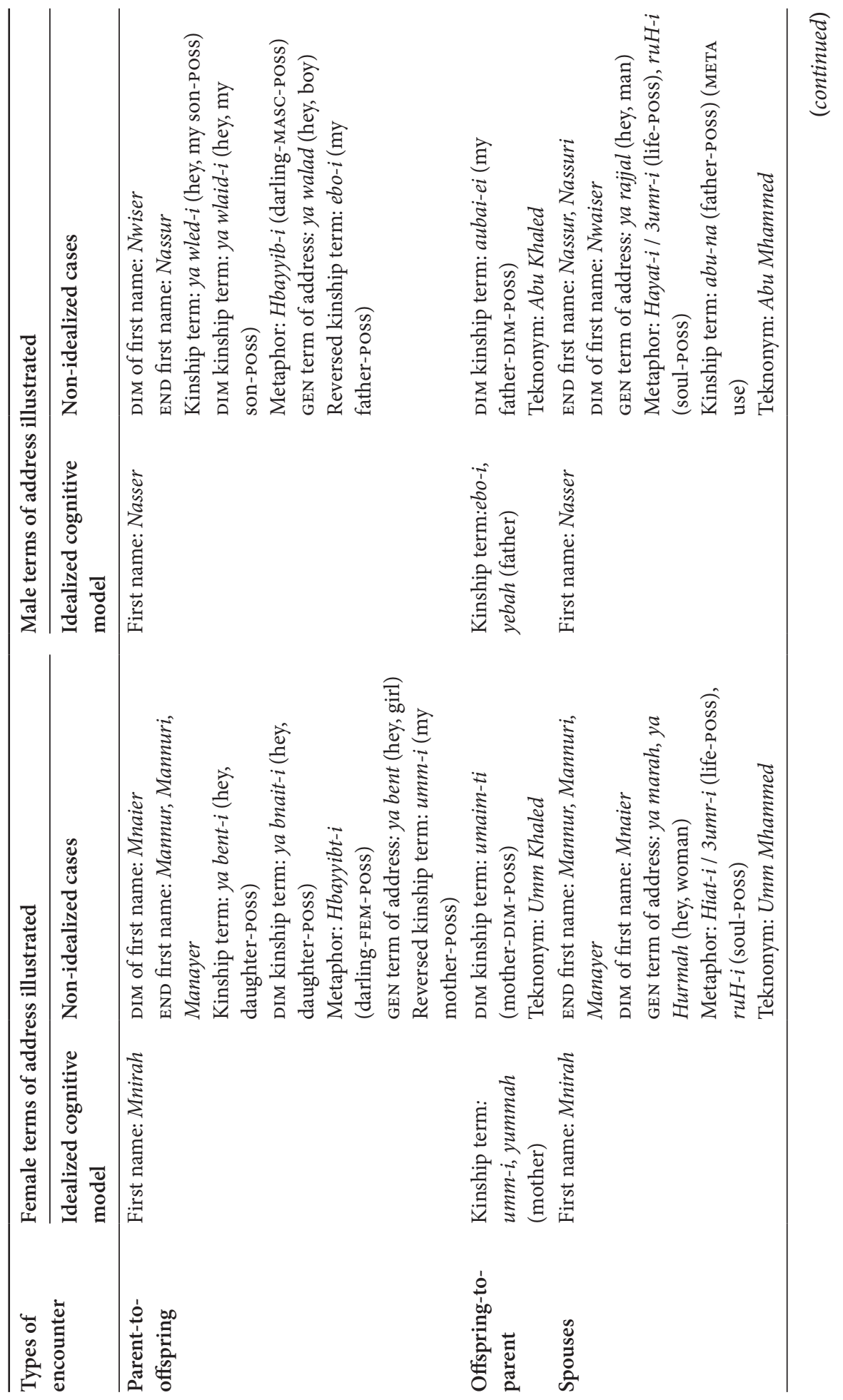




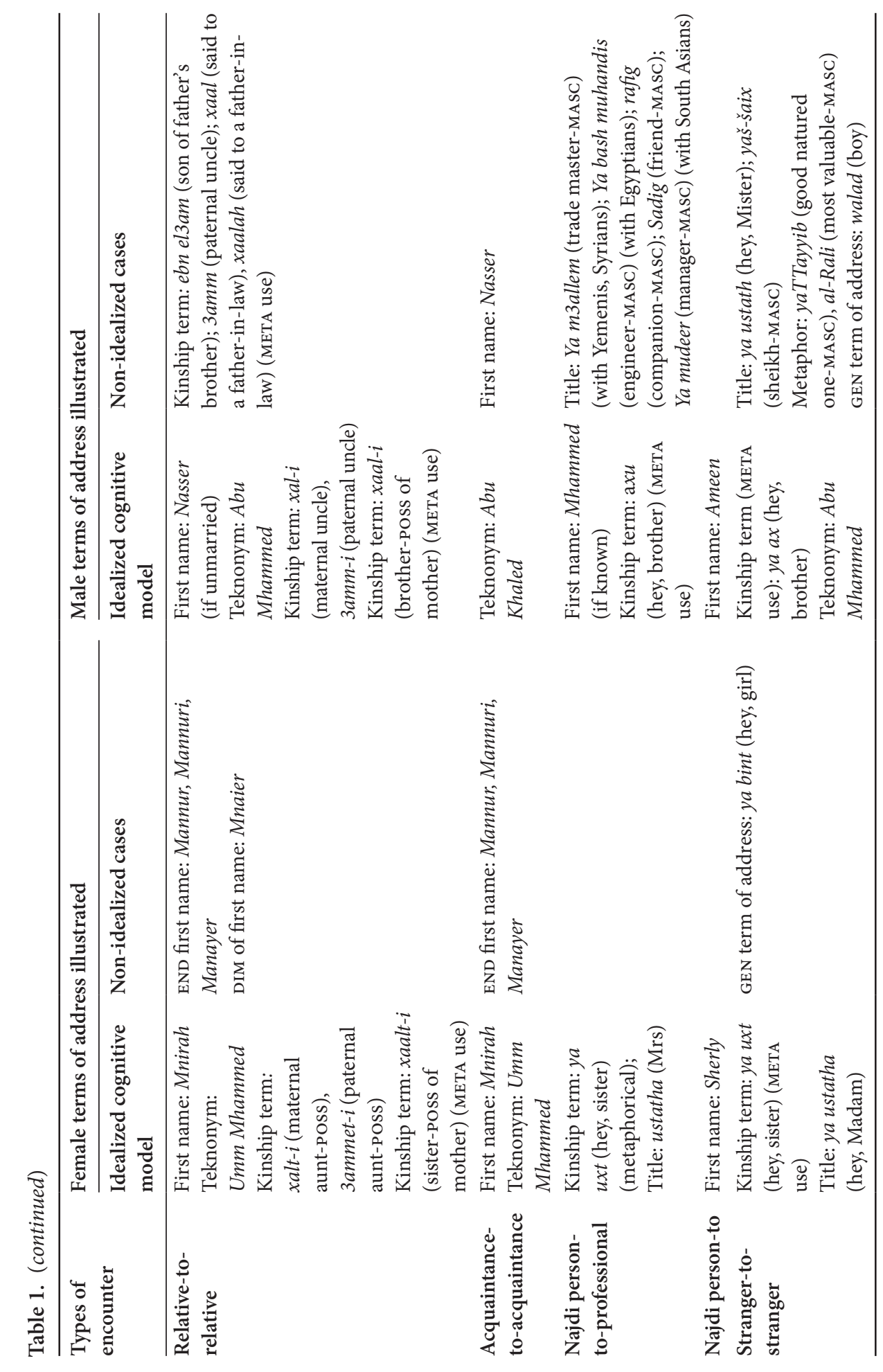


observers in error because it includes many rows corresponding to the different types of encounter between interactants, which magnifies, for instance, the number of occurrences of first names and kinship terms. The actual occurrence of such term of address in real life is different, whereby the teknonym and the first are attested in oral (assumed knowledge) and written reports to be the most prototypical and central term of address in Najdi Arabic. An exception to this is that Najdi people do not address an unmarried young lady with a teknonym. Bin Towairesh (2012, 243) points out that teknonyms are mostly used "to address friends, co-workers, family peers, in addition to superiors and elders. This form is very versatile because it functions on different levels. It expresses solidarity and intimacy when used with peers, but can also express reverence and extreme respect when used with superiors and elders."

\subsection{Propositional structure of Najdi Arabic address system}

As defined by Lakoff $(1987,343)$, propositional structure is part of "a theory of image representation," whereby "visual scenes are represented by arbitrary symbols which are linked together in network structures" to construct a frame. Fillmore $(1982,117)$ defines a frame as "an abstract structure of expectations which brings with it roles, purposes, natural or conventionalized sequences of event types, and all the rest of the apparatus that we wish to associate with the notion of "frame." Fillmore et al. $(2003,305)$ note that frames include frame elements such as agent, experiencer, goal, etc. Taking frames from the cognitive realm, Goffman $(1974,155)$ defines them as "principles of organization which govern events - at least social ones - and our subjective involvement in them." Thus, each type of encounter in Table 1 constitutes a social frame, wherein the selection of the right term of address is determined not only by the type of interactants' age, gender, and status in face-toface interaction but also by the type of context in which they find themselves.

Najdi Arabic includes twelve different social frames, in which the first name and the teknonym are used in eleven of them as Idealized and salient, and tend to alternate in use, with the kinship term being used in three encounters as Idealized and seven encounters as non-Idealized. The first name is found in equal (siblings, spouses, relatives, and acquaintances) and unequal (parent-offspring, elderly-young, and Najdi person-domestic worker) encounters in the system. In equal encounters, they are often reciprocated while in unequal ones they are asymmetrical, requiring other forms of address than the first name. In general, the teknonym is more overly found among males than among females, leading to unequal encounters between the young and the elderly. In terms of non-Idealized models, the DIM of first name, END first name, and the kinship term are part of the menu, with metaphor occupying a less important position in the system but a more important one if compared to its use in the Tunisian Arabic system of address. 


\section{Sami Ben Salamh, Zouheir Maalej and Mohammed Alghbban}

\subsubsection{Idealized Cognitive Models}

Regarding the Idealized models among peers, the first name and the teknonym are used differently by men and women. Young and middle-aged females tend to prefer the first name to address each other as a form of closeness while the elderly tend to prefer the teknonym as a form of formality and deference. That young and adult females tend to avoid the teknonym might be attributed to formality or the fact that they feel that it might make them appear older. In contrast, middle aged and elderly men tend to use the teknonym while young males tend to address each other using the first name. Male and female young people address their elders using the teknonym as a sign of formality and deference while in young male-to-older female encounters the teknonym is not just motivated by formality and deference but also counts as a strategy of avoidance of the first name. Obviously, the teknonym used by young people to address their elders across gender is not reciprocated by the elders to young people, who find themselves addressed through the first name. There is one exception to this use: Young males may be addressed via a teknonym as a way of endearing them and flattering their projected manhood. Among siblings and between parents and their children, the first name is the default term of address, with the teknonym used among siblings with an elderly sister for deference and between two brothers when a third party is present.

Children overly address their parents with the kinship term. Arabs tend to give much importance to kinship emotions, relations, and obligations (El Guindi 2012; Guindi and Al-Othman 2013), the reason being that most Arabs construct social relations grounded in family ties. In spite of this importance of kinship among Arabs, this frame where people are addressed with a kinship term is of low frequency, occurring only three times in Table 1 within and outside the family. Between spouses, the first name is the default term of address.

The Idealized cognitive models of first name, teknonym, and kinship term are best represented by relatives across gender. The first name is reciprocated among young relatives. However, the teknonym is used by the young to show deference to the elderly while it is used among middle aged and the elderly with males. Furthermore, the kinship term is used both non-metaphorically among relatives and metaphorically to address one's spouse's parents. For instance, ya xaalt-i (sister-Poss of mother) is used to address one's mother-in-law when she is not young enough. Among acquaintances, the teknonym is the default term among males while the first name is the default one among close females, with the teknonym being reserved among the females for more formal contexts.

Outside the Najdi family, the kinship term is used metaphorically with professionals and strangers. However, as mentioned earlier on in the Introduction, a teknonym may be elicited from strangers by a Najdi person, literally asking the person addressed for his eldest son's first name to form an online teknonym for the 
stranger. Both the kinship term and the teknonym may be used by Najdi people to sympathize and construct closeness with professionals and strangers. With female professionals and strangers, a professional title may be used in formal, professional settings. With domestic workers, Najdi people use the first name across gender.

\subsubsection{Non-Idealized Cognitive Models}

So far Idealized Cognitive Models of address in Najdi Arabic have been demonstrated to include a restricted set of term of address including mainly the teknonym, the first name, the non-metaphoric kinship term with relatives, and the metaphoric kinship term with acquaintances and strangers. Non-Idealized models, however, are more numerous as Table 1 clearly shows. But, as mentioned earlier on, numerical counts should not be taken for actual occurrence or frequency in real social contexts. In terms of the non-Idealized models among peers across gender, the DIM of the first name, the END of the first name, as well as the kinship term can be used. However, the DIM is reserved for teasing contexts, endearment is prevalent among male and female young people, and metaphor is overly used among young and middle-aged people. Between the young and the elderly, the kinship term is used non-metaphorically among close relatives and metaphorically among distant relatives.

By far, in Najdi Arabic the elderly-young and the parent-offspring dyads are the two encounters which use a battery of term of address that no other type of encounter puts into use. Indeed, six different non-Idealized models can be mentioned, namely, DIM of first name (scolding use), END first name, kinship term, DIM kinship term, metaphor (with endearment), a GEN term of address (scolding use), and a positive attribute (flattering use). In the parent-offspring dyad, a reversed kinship term may be used in contexts of high endearment. Very much like these two dyads, siblings have a choice of terms of address depending on contexts such as the DIM of first name (in teasing contexts), the END first name, the (DIM) kinship term, and even the teknonym between young brother/sister to elder brother/sister for deference. In contrast, the offspring-parent dyad has a limited resource such as the DIM kinship term and the teknonym, with the latter exclusively used in private contexts when no other person is present in the dyad beside a son and his mother/father.

Between spouses, the situation is slightly different since the question of private and public space is relevant at this point. In the private space, spouses have a choice of terms of address depending on situation. The husband may make use of the END first name, the DIM of first name (mostly in teasing contexts), GEN term of address, and metaphor. In the public space, a husband would address his wife with a teknonym since it is not preferred to pronounce her name publicly while she may address him in private using an END first name, the DIM of first name (mostly in teasing contexts), a kinship term, a GEN term of address, and metaphor. In the presence of 
a third party, a wife is expected to address her husband using the teknonym as a formal term of address. Between relatives, females would address each other with the END first name and the DIM of first name (mostly in teasing contexts) while male relatives may use a metaphorized kinship term mostly with very old cousins. Among female acquaintances, the END first name is used by young ladies to address each other while among male acquaintances the first name is more common.

Outside the family circle, there is no term of address to use with professional females while professional males are addressed with a title depending on their nationality as spelled out in Table 1 . The GEN term of address is used by an elderly Najdi male/female to address a younger male/female stranger. Najdi males address young male strangers using a professional or social title.

Thus, with Idealized and non-Idealized Cognitive Models of address, factors such as age, formality, and gender seem to determine what term of address to use in each encounter across relatives, acquaintances, and strangers in Najdi Arabic. Gender, in particular, seems to play a role in selecting terms of address across encounters, resulting in the non-reciprocation of terms of address between males and females especially when a third party is present in the dyad and in the public sphere. The next sub-section addresses the image schematic reflection of the different types of encounter.

\subsection{Image-schematic structure of Najdi Arabic address system}

Najdi Arabic terms of address offer three possible image-schematic possibilities, namely, HORIZONTALITY, VERTICALITY, and COmbined HORIZONTALITY-VERTICALITY. In all dyads across Idealized and non-Idealized models, the first name, which occurs nine times out of the twelve encounters, unambiguously motivates an image schema of social HORIzONTALITY. The use of the first name in conversation is associated with solidarity and closeness. Except for the GEN term of address, most, if not all, terms in the non-Idealized columns in Table 1, like the first name, reflect a HORIZONTALITY image schema. On the other hand, verTiCALITy is exemplified through the GEN term of address as used in the elderly-young, parent-offspring, and strangers encounters. Indeed, since this term is used by older people to younger ones in all these encounters (especially, when it is used as an attention-getting device or as part of warning), older people seem to hint at a social stratification where they position themselves higher on the social plane.

However, the teknonym, which is used seven out of twelve times, motivates both social HORIZONTALITY and VERTICALITY, thus highlighting the pragmatics of the teknonym, which is highly sensitive to the types of encounter. For instance, when elderly females and middle-aged as well as elderly males tend to use the 
teknonym among each other, they are understood to be peers, therefore they use it to show social HORIZONTALITY. In this context, teknonyms offer a big advantage in interpersonal interaction across age, gender, and social status as they tend to abstract away social hierarchy and status, especially when they are reciprocated. Conversely, when young people use the teknonym to address the middle-aged and the elderly, it is for deference, and that, therefore, it is used to show social VERTICALITY. Thus, it is the type of encounter (including the social status and age of members of the dyad) that determines whether the teknonym is used with an intention of HORIZONTALITY OO VERTICALITY.

\subsection{Metaphorical mappings of Najdi Arabic address system}

Metaphorical mappings feature in two guises in Najdi Arabic across Idealized and non-Idealized models. One guise relates to the use of the kinship term among relatives, acquaintances, and strangers such as in yaxti (hey, my sister) or ya xoy (hey, my brother), thus creating the conceptual metaphor, NON-KIN IS KIN. The use of a kinship term among strangers of opposite sexes cancels out the sexual contexts. In other words, the invocation of a kinship term such as ya xoy (my brother) or yaxti (my sister) establishes "sexual detachment" (Bin Towairesh 2012, 76) between interactants, presenting them in a frame of reference where their relationship is metaphorically asexual since they become in theory forbidden to each other. A unique use of the kinship term occurs between spouses, whereby a wife and a mother make use of the kinship term abu-na (our father) to conceptualize her husband in the presence of their children or in other family contexts. Such a use is extremely emotional, where the wife, so to speak, transforms herself through the inclusive genitive "our" into a daughter of her own husband, which suggests the culture-specific conceptual metaphor, A MARRIED WOMAN IS THE CHILD OF HER HUSBAND.

In non-Idealized models, metaphor is used in another guise. In anticipation, and more frequently than in Tunisian Arabic, Najdi Arabic parents and relatives conceptualize young males in zoological terms, which can be captured in the conceptual metaphor, A YOUNG HUMAN IS A SKILLFUL HUNTER/ PREDATOR as conveyed by the terms of address ya Sagr (hey, falcon) and ya Deeb / ya Deeban (hey, wolf). The latter term is highly used in Najdi Arabic. In contrast, between spouses metaphors such as Hiat-i / 3umr-i (my life) and $r u H-i$ (my soul) are used to conceptualize each other according to the conceptual metaphor, A MAN/WOMAN IS A LOVER. 


\subsection{Metonymical mappings of Najdi Arabic address system}

In Najdi Arabic, the teknonym establishes a PART-WHOLE metonym, which reduces the various social roles the individual plays in society to parenting, i.e. fathering or mothering. This PART-WHOLE metonym actually makes publicly salient the fact that the interlocutor is a progenitor, thus downplaying other roles played in society. This generic PART-WHOLE metonym can be more precisely captured in the more specific metonymy, MAN/WOMAN-FOR-PROGENITOR. Conceptualizing one's wife metaphorically as a lover singles out her being a woman, which seems to be inconsistent with the PART-WHOLE metonym carried by the teknonym (e.g. umm Khaled). Socially, the teknonym restricts the function of a woman that begets children to a mothering function.

\section{Tunisian Arabic address system}

So far, it has been demonstrated that the address system in Najdi Arabic is dominated by the first name, the teknonym, and the kinship term as central Idealized Cognitive Models of address, with numerous non-idealized terms of address as shown in Table 1. In this section, the Tunisian Arabic system of address is investigated. But before this, a few words about the Tunisian Arabic dialect are in good order. Unlike Najdi Arabic, which is a local dialect in Saudi Arabia, Tunisian Arabic is a national dialect spoken by all Tunisians even though some variety could be found across the country. Owing to colonization, Tunisian Arabic is known to be a code-mixed dialect, including French and Arabic. The distribution of the terms of address in Tunisian Arabic is spelled out in Table 2 below.

In contrast to Najdi Arabic, a noticeable feature about Table 2 above is that teknonymy is alien to the system of address in Tunisian Arabic. In fact, teknonyms neither exist in Tunisia nor in Sudan, Libya, Algeria, and Morocco. As done with Najdi Arabic, in the following sub-sections the address system in Tunisian Arabic is differentiated into Idealized and non-Idealized models in 4.1. 


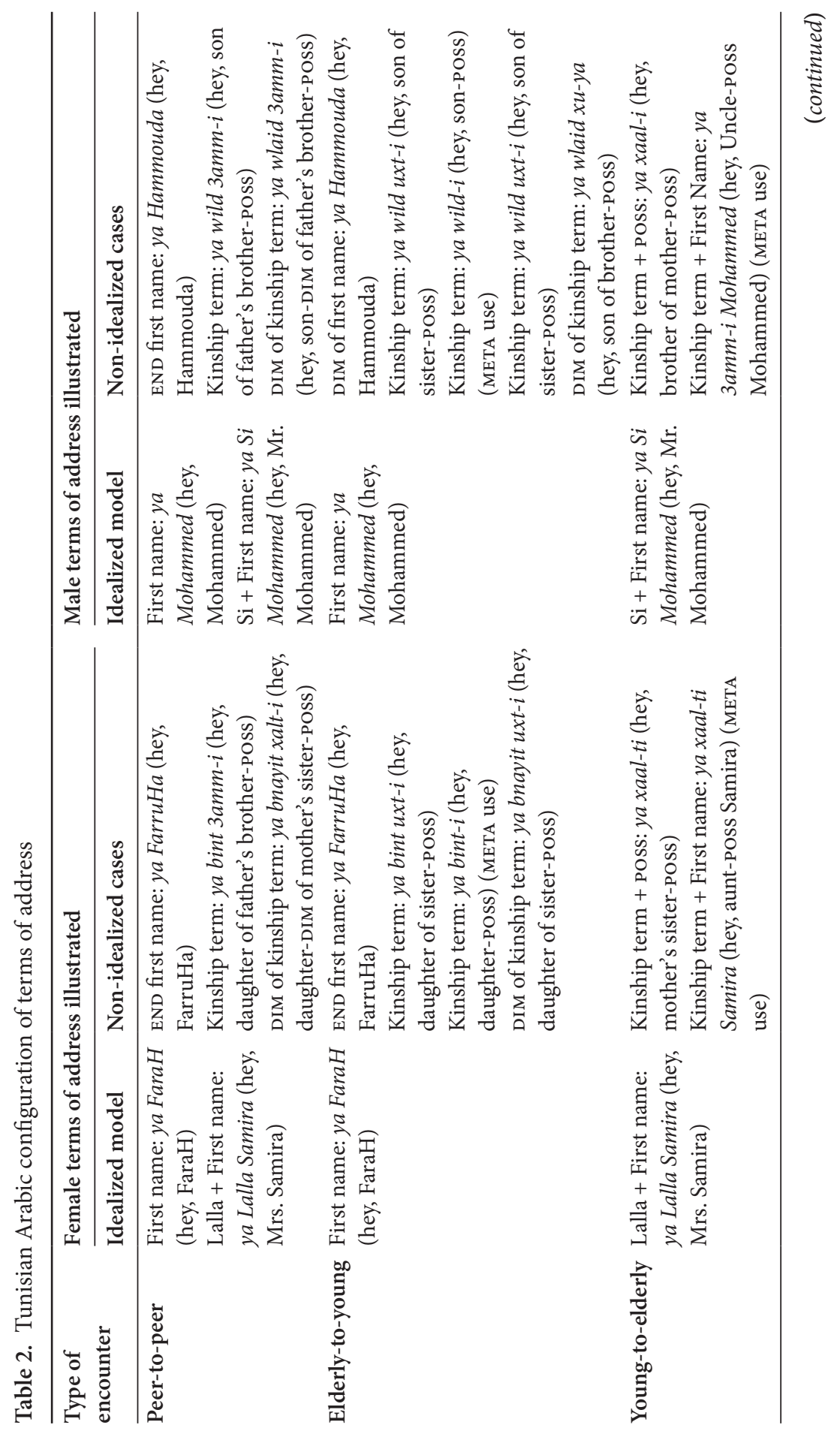




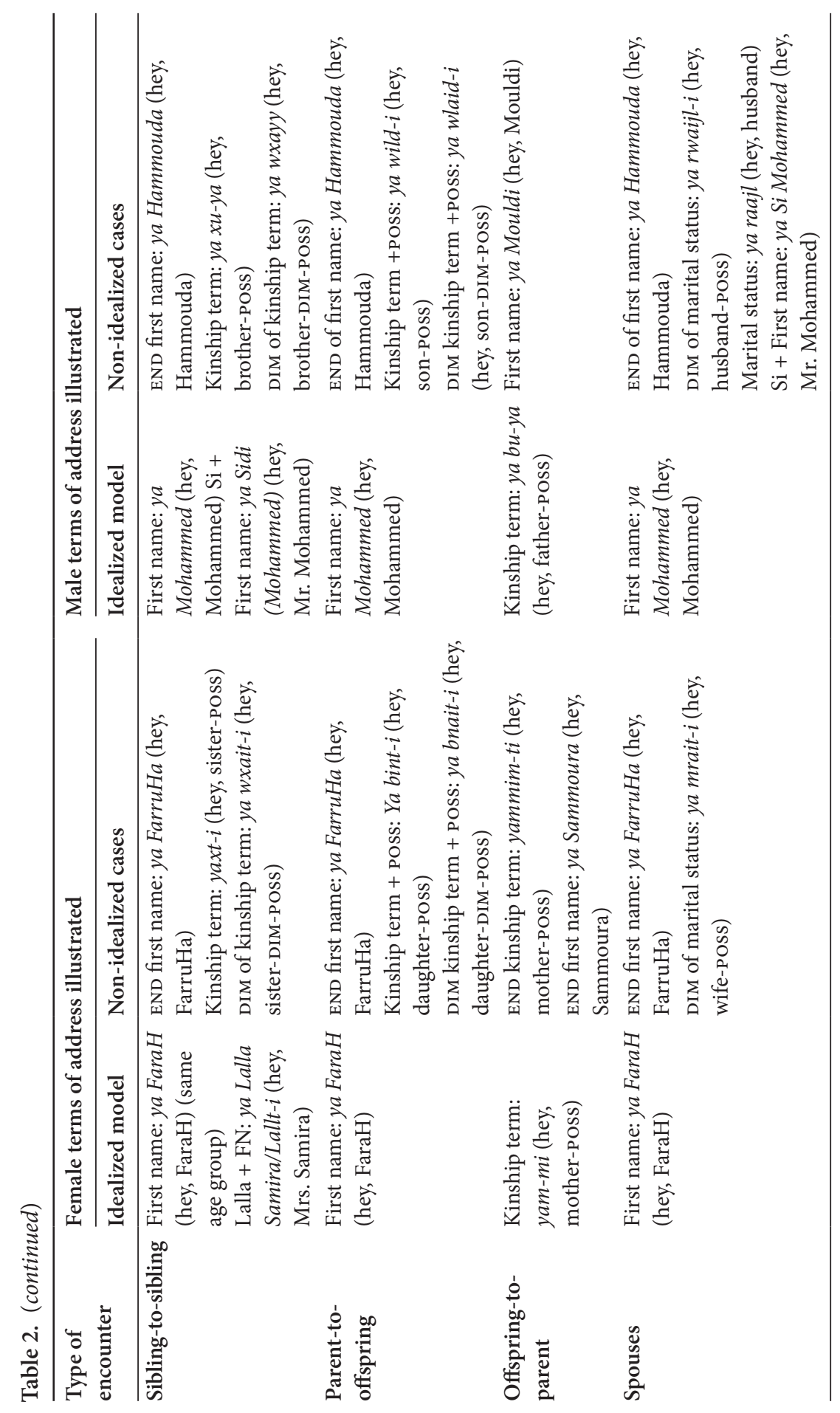




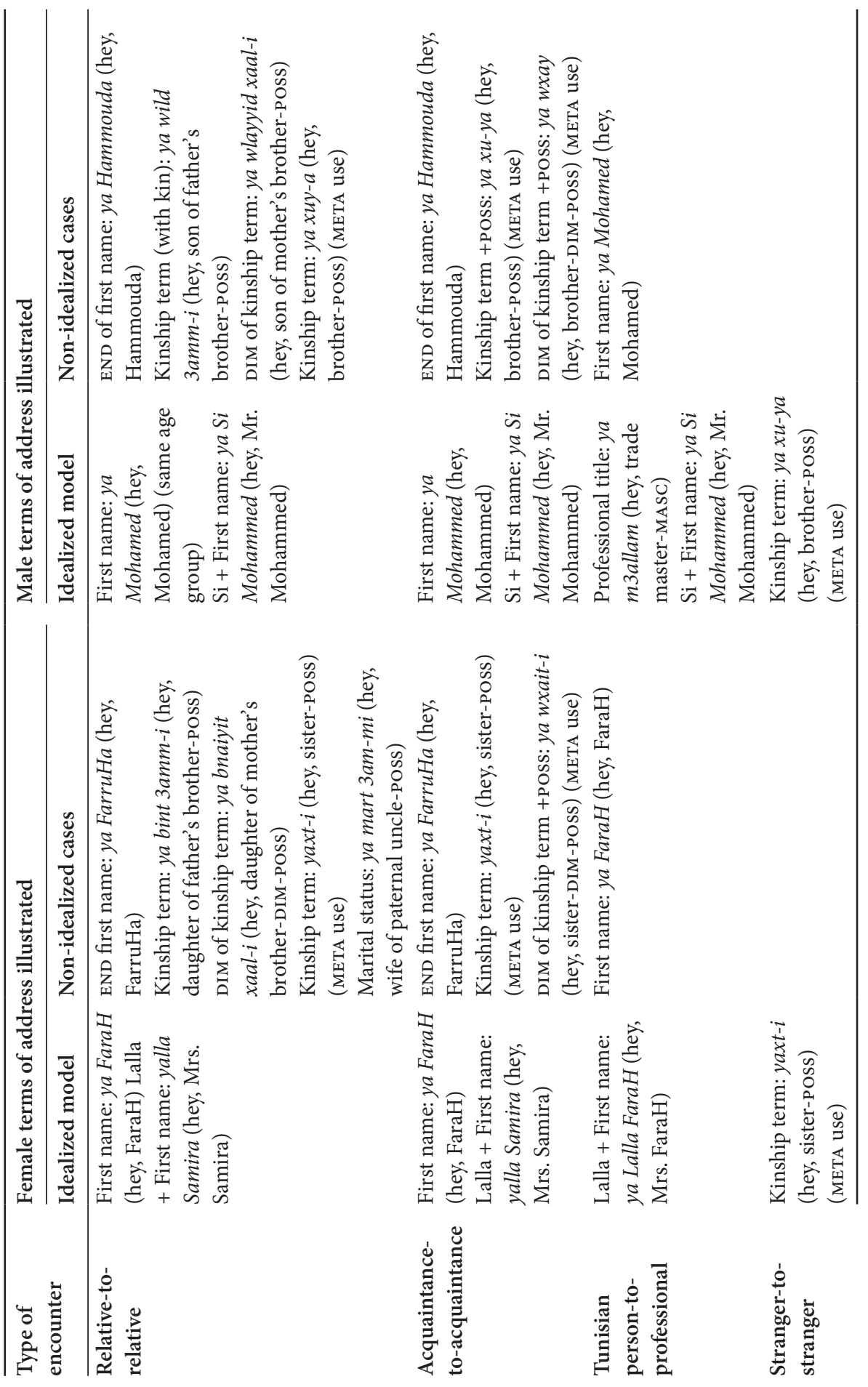




\subsection{Propositional structure of the Tunisian Arabic address system}

As with Najdi Arabic, there are as many frames in Tunisian Arabic as types of encounter between interactants in conversation. Individuals know the conventional ways of negotiating their status with the others relying on variables such as age, closeness/distance, and deference to construct the frame. As transpires from Table 2 above, the first name, the Si/Lalla + first name, and the kinship term are Idealized and prototypical terms of address. The first name occurs eight times and the Si/Lalla + first name six times in the eleven types of encounter, which means nine occurrences alone or with the other in eleven encounters while the metaphoric and non-metaphoric kinship terms occur in two encounters only. However, non-Idealized term of address are more prolific, including first names and kinship terms tainted by endearment, the diminutive, and metaphor as well as other terms such as marital status and even $\mathrm{Si}+$ first name in the wife-to-husband dyad.

\subsubsection{Idealized Cognitive Models}

Among peers, the first name is the default term of address across gender, with $\mathrm{Si}$ / Lalla + first name used in formal contexts by middle-aged and elderly peers. The same first name and Si/Lalla + first name are used among siblings, relatives, wife-tohusband, acquaintances, and professionals. However, while the first name is used among same age interactants to show closeness and familiarity, the Si/Lalla + first name shows social distance and deference to elder brothers and sisters, and elderly relatives, acquaintances, and professionals. It should be noted that $\mathrm{Si} / \mathrm{Lalla}+$ first name occurs in male-female and female-male directionalities. Between young and old, there exists honorification, which is defined by Agha $(1994,277)$ as "relationships involving social status, respect, or deference between communicative interactants." As a cultural value, deference or honorification is seen as the duty of the youth to show their respect for their elders in consideration for their advanced age, social status, and wisdom. Between the elderly and the young, the first name is used by the middle-aged and elderly to address the young while the young unfailingly use the deference term $\mathrm{Si} /$ Lalla + first name.

Parents address their children with a first name while offspring address their parents with the kinship terms yam-mi (hey, mother) and ya bu-ya (hey, father). Spouses use the first name in private and in public, and never shift address between the first name and Si/Lalla + first name as Najdi spouses may do in the public space. Among non-professionals and professionals, the Si/Lalla + first name is the rule among ladies and a professional title is used with males. The Si/Lalla + first name is reciprocated among non-professionals and professionals since all of them are Tunisians. To strangers, Tunisian Arabs reserve a metaphorized kinship 
term. Maalej $(2010,148)$ found that terms of address with non-acquaintances or strangers in Tunisian Arabic are "motivated by the creation of familiarity and solidarity and the minimization of distance ... through the injection of kinship-and religion-related terms."

\subsubsection{Non-Idealized Cognitive Models}

In non-idealized cases, Tunisian Arabic creates more frames, where the END first name, the kinship term, the DIM of kinship term, and the metaphorized kinship term are used in most encounters among males and females. What characterizes these terms is the fact that they are accompanied by endearment, emotionality, and metaphoricity. Slobin $(1963,201)$ states that "kinship takes precedence over familiarity in determining solidarity. Within the family, long-established intimacy takes precedence over the status of age in determining pronominal usage, but, in the absence of such intimacy, the status rule of age takes over." Exceptions to these non-idealized frames are the encounters between non-professionals and professional, who use the first name, and among strangers, who do not have a non-idealized form to address each other. There is a particular, unreciprocated use of Si + First name (ya Si Mohammed: hey, Mr. Mohammed) as used by a wife to her husband as a sign of deference not so much for age but in reverence of him for being the head of the family, which use is almost obsolete nowadays. There are also two restricted uses of the End first name with mothers and the first name with fathers when relations between parents and offspring are relaxed.

Thus, in Idealized and non-Idealized Cognitive Models of address in Tunisian Arabic, what seems to determine the term of address to use among interactants is primarily the factor of age and to, a lesser degree, the factor of formality. Apart from Lalla + first name being used with females, the factor of gender does not seem to play a role across encounters, resulting in the use of the term of address by females and males to other females in private and public places.

\subsection{Image-schematic structure of the Tunisian Arabic address system}

In light of the Idealized and non-idealized frames described in 4.1, it is plausible to correlate the first name Idealized model with the image schema of HORIZONTALITY as between same age peers, spouses, relatives, and acquaintances. However, the $\mathrm{Si}+$ first name as used by a younger brother to an elder one, establishes VERTICALITY within the sibling-to-sibling encounter in the sense of deference. On the other hand, the Si/Lalla + first name as used among peers and relatives triggers the same image schema of VERTICALITY but as motivated by formality between interactants. In using the image schema of VERTICALITY, Tunisians seem to favor 
honoring older people and keeping their distance towards peers and relatives. As to the non-idealized cases, since the term of address with strangers is recruited from within the kinship system, addressing them via a metaphorical kinship term, the image schema is FAR-CLOSE, which is manipulated by interactants to bring the other closer to the self. When non-professionals address professionals, the first name is used, suggesting the image schema of HORIZONTALITY.

In the Arab world, the Tunisian society is known for its fairly equalitarian system of gender relations, whereby HORIZONTALITY is expected to be the case in interpersonal interactions especially among peers, which is actually realized through the use of the first name. As early as the second half of the 20th century, women had the right to education, right to a decent job, and right to free expression. These rights have greatly contributed to leveling relations within the family and society, with co-education prevailing at schools and universities and lack of separation of sexes in public places, which makes them candidates to HORIZONTALITY. In parallel, the image schema of VERTICALITY is governing age relations independently of men-women relations in Tunisia. In other words, a younger male should address an older female using the deference term Lalla + first name. Conversely, a younger female should address an older male using the deference term $\mathrm{Si}+$ first name. Thus, in the Idealized dimension, the first name is known to fit the social world perfectly while the Si/Lalla + first name may be said to fit the Tunisian's understanding of the social world less perfectly since social VERTICALITY (i.e. man-woman equality) also applies to old women as addressed by younger men.

\subsection{Metaphorical mappings of the Tunisian Arabic address system}

In the Idealized models with strangers, kinship terms are used metaphorically across gender, which has the effect of creating in the social space the conceptual metaphors, NON-KIN IS KIN. As part of the non-Idealized model, children may address older male and female relatives such as their paternal and maternal aunts' husbands using a metaphorical expression from within the kinship system such as ya $3 a m m-u$ (hey, uncle), which is reminiscent of Najdi Arabic's xaal and xaalah (as used with one's parents-in-laws). Such a use promotes the status of those addressed to kin as suggested by the conceptual metaphor, DISTANT RELATIVE IS KIN.

\subsection{Metonymical mappings of the Tunisian Arabic address system}

In Tunisian Arabic, as part of the non-Idealized cognitive model, children may address their paternal and maternal uncles' wives as ya mart 3amm-i (hey, my paternal uncle's wife) and ya mart xal-i (hey, my maternal uncle's wife), respectively. 
However, a paternal uncle's wife and a maternal uncle's wife will not be addressed using the martial status, which follows from the cultural thinking that the marital status is the best destiny for a woman. A young male or female may address his or her elder brother's wife as ya mart Sidi (hey, my elder brother's wife). Although such terms of address are progressively being replaced by more neutral ones such as ya tata, they emphasize the importance of the marriage institution via the address system. A wife may also address her husband with the DIM of marital status as in ya rwaijl-i (hey, my husband) for endearment or simply a marital status term of address such as ya raajil (hey, husband). Such terms of address invoke the marital status of the women/men addressed, and are motivated by the WOMAN-FOR-WIFE and MAN-FOR-HUSBAND metonymies, thus highlighting their state of being a wife/ husband rather than a woman/man or a mother/father.

\section{Discussion}

The current article has argued for two distinct address systems in Najdi Arabic and Tunisian Arabic along Lakoff's theory of Idealized Cognitive Models. The findings are summed up in the following table:

Table 3. Najdi Arabic and Tunisian Arabic address systems compared

\begin{tabular}{|c|c|c|c|c|c|}
\hline Dialect & Idealization & $\begin{array}{l}\text { Propositional } \\
\text { structure }\end{array}$ & $\begin{array}{l}\text { Image-schematic } \\
\text { structure }\end{array}$ & $\begin{array}{l}\text { Metaphorical } \\
\text { mappings }\end{array}$ & $\begin{array}{l}\text { Metonymic } \\
\text { mappings }\end{array}$ \\
\hline Najdi & Idealized & First name & HORIZONTALITY & & \\
\hline \multirow[t]{17}{*}{ Arabic } & & Kinship term & & ON-KIN IS KIN & \\
\hline & & Teknonym & HORIZONTALITY & & MAN/WOMAN- \\
\hline & & & VERTICALITY & & FOR-PROGENITOR \\
\hline & Non-idealized & Kinship term & HORIZONTALITY & NON-KIN IS & \\
\hline & & END kinship & & KIN & \\
\hline & & term & & A MARRIED & \\
\hline & & DIM kinship & & WOMAN IS THE & \\
\hline & & term & & CHILD OF HER & \\
\hline & & END first name & & HUSBAND & \\
\hline & & DIM first name & & A HUMAN IS & \\
\hline & & Metaphorized & & A SKILLFUL & \\
\hline & & term & & HUNTER/ & \\
\hline & & Professional & & PREDATOR & \\
\hline & & title & & A MAN/WOMAN & \\
\hline & & & & IS A LOVER & \\
\hline & & Teknonym & VERTICALITY & & \\
\hline & & Gendered term & & & \\
\hline
\end{tabular}


Table 3. (continued)

\begin{tabular}{|c|c|c|c|c|c|}
\hline Dialect & Idealization & $\begin{array}{l}\text { Propositional } \\
\text { structure }\end{array}$ & $\begin{array}{l}\text { Image-schematic } \\
\text { structure }\end{array}$ & $\begin{array}{l}\text { Metaphorical } \\
\text { mappings }\end{array}$ & $\begin{array}{l}\text { Metonymic } \\
\text { mappings }\end{array}$ \\
\hline Tunisian & Idealized & First name & HORIZONTALITY & & \\
\hline \multirow[t]{7}{*}{ Arabic } & & Kinship term & & NON-KIN IS & \\
\hline & & & & KIN & \\
\hline & & $\begin{array}{l}\text { Si/Lalla + First } \\
\text { name }\end{array}$ & VERTICALITY & & \\
\hline & Non-idealized & END first name & HORIZONTALITY & DISTANT & WOMAN-FOR- \\
\hline & & Kinship term & & RELATIVE IS & WIFE/MAN FOR \\
\hline & & $\begin{array}{l}\text { DIM kinship } \\
\text { term }\end{array}$ & & KIN & HUSBAND \\
\hline & & $\begin{array}{l}\text { Marital status } \\
\text { term }\end{array}$ & & & \\
\hline
\end{tabular}

It should be noted that Najdi Arabic includes an encounter which does not exist in Tunisian Arabic, namely, the Najdi person-domestic worker. Owing to the big size of families, many people in Saudi Arabia feel the need to hire domestic workers or helpers. Moreover, the necessity for mobility requires them to hire a private chauffeur. Although the first name is the only Idealized model used with domestic workers, it cannot be equated with closeness. Moreover, it should be noted that Najdi Arabic offers its speakers a larger battery of address terms than Tunisian Arabic does. A simple count of terms of address in Tables 1 and 2 yields forty address options for Najdi Arabic but only twenty-eight options in Tunisian Arabic. This may testify to the complexity of social relations within Najdi society.

Although Najdi Arabic and Tunisian Arabic converge in addressing strangers in Idealized and non-idealized scenarios, they tend to diverge everywhere else in their address systems. The significance of this divergence is that the address system of Najdi Arabic hinges mainly on the first name and the teknonym while Tunisian Arabic builds its system mainly on the first name and the deference term $\mathrm{Si} /$ Lalla + first name. While the wife's first name goes public in Tunisian Arabic as an Idealized and prototypical term, it may be substituted in Najdi Arabic in public by the teknonym, which means that the first name may not be reciprocated across age and gender in public. Thus, Najdi Arabs tend to negotiate the first name and the teknonym across gender while Tunisian Arabs seem to be intransigent on negotiating the deference form (Lalla + first name) for the first name when it comes to addressing one's wife or other ladies.

The HORIZONTALITY-VERTICALITY schema created by the terms of address in Najdi Arabic and Tunisian Arabic, should not mislead us into thinking that the former is fully animated by HORIZONTALITY and the latter by VERTICALITY. In Najdi Arabic, it seems that people are trading VERTICALITY for HORIZONTALITY as an 
Idealized, prototypical image schema accompanying the teknonym. Although the teknonym creates a HORIZONTALITY schema in Najdi Arabic in its Idealized use, this situation seems to conflict with social verTiCALITY as a feature of the Najdi Arabic social world, where man and woman are brought up to be somewhat different in status. It is worth noting that this situation is progressively changing. On the other hand, the deference term Si/Lalla + first name, which creates social vERTICALITY, may be hard to reconcile with the Tunisian society known for its more liberal and equalitarian mentality.

Metaphor-wise, Najdi Arabic and Tunisian Arabic also diverge. Najdi Arabic departs from Tunisian Arabic in using various metaphors from the animal kingdom to address young and even older males such as Deeb/Deeban (wolf) and Sagr (falcon). Such metaphors are governed by the conceptual metaphor, A HUMAN IS A SKILLFUL HUNTER/PREDATOR. Moreover, it is not infrequent for spouses to rely on metaphors such as Hiat-i/3umr-i (my life) and ruH-i (my soul), which are supported by the conceptual metaphor A MAN/WOMAN IS A LOVER. Likewise, $a b u-n a$ (our father) is used by a wife to her husband, which can be captured by the conceptual metaphor, A MARRIED WOMAN IS THE CHILD OF HER HUSBAND. With strangers, metaphorized kinship terms are used (A NON-KIN IS KIN). In Tunisian Arabic, metaphor seems to be restricted in use to address strangers (A NON-KIN IS KIN) and distant relatives (DISTANT RELATIVE IS KIN).

At the metonymic level, Najdi Arabic and Tunisian Arabic also diverge even though they adopt the same PART-WHOLE metonymic model. In Najdi Arabic, the teknonym hinges on progeny, thus emphasizing the progenitive social role of men and women at the expense of other roles. Teknonyms as in umm Khaled (Khaled's mother) and abu Khaled (Khaled's father) highlight the fathering and mothering roles of spouses, and are motivated by the MAN/WOMAN-FOR-PROGENITOR metonym. In contrast, in Tunisian Arabic the PART-wHOLE metonym is biased to a man's (or a woman's) marital status as in ya mraiti (hey, my wife) and ya rwaijli (hey, my husband), which highlights the social role of being a wife and a husband, respectively. These uses are motivated by the WOMAN-FOR-WIFE/MAN FOR HUSBAND metonymy.

\section{Conclusion}

In this article, the Najdi Arabic and Tunisian Arabic address systems have been compared and contrasted. Najdi Arabic is found to be mostly dominated by the Idealized, prototypical term of address of first name, teknonym, and kinship term while Tunisian Arabic is found to be dominated by the first name, the Si/Lalla + first name, and the kinship term. The two systems are shown to include a more 
numerous set of non-Idealized term of address, with Najdi Arabic outnumbering its Tunisian counterpart, which may testify to more sophisticated social relations and interactions in Najdi society.

In Najdi Arabic, the pragmatics of the teknonym resides in its frequent use as a leveler, creating symmetry between interactants, reciprocation of the term, and social HORIzONTALITY across relatives, acquaintances, and gender. However, the same term of address might be used for formality, thus creating asymmetry, non-reciprocation, and social VERTICALITY across gender and age in certain encounters. Between spouses, the teknonym is the most Idealized and prototypical term of address, with the first name becoming non-prototypical in the extended family and the public sphere. As for metaphor, Najdi Arabic turns out to be more poetic, making use of metaphor and metaphorized terms to address relatives, offspring, spouses, and even strangers. As to metonymy, Najdi Arabic capitalizes on progeny in using the teknonym as an Idealized model.

In Tunisian Arabic, the first name is used and reciprocated as a default term across relatives, acquaintances, and gender, with the deference term Si/Lalla + first name as motivated by age. The first name motivates symmetry and HORIZONTALITY while the Si/Lalla + first name suggests asymmetry, non-reciprocation, and VERTICALITY, except in formal settings when it is used among peers. Between spouses, the first name is the default term in private and public spheres. Regarding metaphor, Tunisian Arabic is less prolific and less poetic than Najdi Arabic in terms of metaphor use, reserving it mainly to distant relatives and strangers. With regard to metonymy, Tunisian Arabic differs from Najdi Arabic by capitalizing on marital status rather than progeny as a non-Idealized model.

Even though the findings about Idealized and non-Idealized terms of address in both dialects may point to a correlation between a given encounter and its dyad as a systematic or even automatic fit, it should not be understood that these terms create an invariable prototype valid for all dyads across relatives, acquaintances, and non-acquaintances as spelt out in Tables 1 and 2 above. On the contrary, terms of address in Najdi Arabic and Tunisian Arabic are sensitive to context, with the same term of address used in different encounters.

\section{References}

Agha, Asif. 1994. "Honorification." Annual Review of Anthropology 23: 277-302. doi:10.1146/annurev.an.23.100194.001425

Al-Khatib, Mahmoud A. 2003. "Address Norms in Jordanian Arabic: A Sociolinguistic Perspective." Grazer Linguistische Studien 59: 1-20. 
Alrabaa, Sami. 1985. "The Use of Address Pronouns by Egyptian Adults: A Sociolinguistic Study." Journal of Pragmatics 9: 645-657. doi:10.1016/0378-2166(85)90057-8

Barakat, Halim. 1993. The Arab World: Society, Culture, and State. Berkeley: University of California Press.

Bin Towairesh, Abdullah. 2012. "The Use of Term of Address in the City of Riyadh, Saudi Arabia." Ph.D. dissertation: University of Queensland.

Bratt Paulston, Christina. 1976. "Pronouns of Address in Swedish: Social Class Semantics and a Changing System." Language in Society 5 (3): 359-386. doi:10.1017/So04740450000717X

Braun, Friederike. 1988. Terms of Address: Problems of Patterns and Usage in Various Languages and Cultures. Berlin: Mouton de Gruyter. doi:10.1515/9783110848113

Brown, Penelope, and Stephen C. Levinson. 1987. Politeness: Some Universals in Language Use. Cambridge: Cambridge University Press.

Brown, Roger, and Albert Gilman. 1960. "The Pronouns of Power and Solidarity." In Style in Language, ed. by T. A. Sebeok, 253-276. Mass.: MIT Press.

Clyne, Michael. 2009. “Address in Intercultural Communication Across Languages.” Intercultural Pragmatics 6 (3): 395-409. doi:10.1515/IPRG.2009.020

Clyne, Michael, Heinz-Leo Kretzenbacher, Catrin Norrby, and Doris Schüpbach. 2006. "Perceptions of Variation and Change in German and Swedish Address." Journal of Sociolinguistics 10 (3): 287-319. doi:10.1111/j.1360-6441.2006.00329.x

Edwards, Derek. 1997. Discourse and Cognition. London: Sage Publications.

El Guindi, Fadwa. 2012. "Milk and Blood: Kinship among Muslim Arabs in Qatar." Anthropos 107: 545-555.

El Guindi, Fadwa, and Wesam Al-Othman. 2013. "Transformationality and Dynamicality of Kinship Structure." Structure and Dynamics 6 (1): 1-18.

Fang, Hanquan, and J. H. Heng. 1983. "Social Changes and Changing Address Norms in China." Language in Society 12 (4): 495-507. doi:10.1017/Soo47404500010216

Farghal, Mohammed, and Abdullah Shakir. 1994. "Kin Terms and Titles of Address as Relational Social Honorifics in Jordanian Arabic." Anthropological Linguistics 36 (2): 240-253

Fasold, Ralph. 1990. The Sociolinguistics of Language. Oxford: Blackwell Publishers.

Feghali, Ellen. 1997. “Arab Cultural Communication Patterns." International Journal of Intercultural Relations 21 (3): 345-378. doi:10.1016/S0147-1767(97)00005-9

Fillmore, Charles J. 1982. "Frame Semantics." In Linguistics in the Morning Calm, ed. by The Linguistic Society of Korea, 111-137. Seoul: Hanshin Publishing Company.

Fillmore, Charles J., Miriam, R. L. Petruck, Josef Ruppenhofer, and A. Wright. 2003. "Framenet in Action: The Case of Attaching." International Journal of Lexicography 16 (3): 297-323.

doi:10.1093/ijl/16.3.297

Givón, Talmy. 1989. Mind, Code and Context: Essays in Pragmatics. Hillsdale, New Jersey and London: Lawrence Erlbaum Associates Publishers.

Goffman, Erving. 1974. Frame Analysis: An Essay on the Organization of Experience. New York: Harper and Row.

Holmes, Janet. 1992. Introduction to Sociolinguistics. London and New York: Longman.

Jones, Doug. 2004. “The Universal Psychology of Kinship: Evidence from Language.” Trends in Cognitive Sciences 8 (5): 211-215. doi:10.1016/j.tics.2004.03.001

Kasanga, Luanga A. 2009. "Language Socialization: The Naming of Non-Kin Adults by African Children and Preadolescents in Intercultural Encounters." Intercultural Pragmatics 6 (1): 85-114. doi:10.1515/IPRG.2009.004 
Kramer, Chris. 1975. "Sex-related Differences in Address Systems." Anthropological Linguistics 17 (5): 198-210.

Lakoff, George. 1982. “Categories: An Essay in Cognitive Linguistics.” In Linguistics in the Morning Calm, ed. by The Linguistic Society of Korea, 139-193. Seoul: Hanshin Publishing Company.

Lakoff, George. 1987. Women, Fire, and Dangerous Things: What Categories Reveal about the Mind. Chicago/London: The University of Chicago Press.

doi: $10.7208 /$ chicago/9780226471013.001.0001

Levinson, Stephen C. 1983. Pragmatics. London: Cambridge University Press.

Maalej, Zouheir. 2010. "Addressing Non-Acquaintances in Tunisian Arabic: A Cognitive-Pragmatic Account." Intercultural Pragmatics 7 (1): 147-173. doi:10.1515/iprg.2010.007

Marmaridou, Sophia S. A. 2000. Pragmatic Meaning and Cognition. Amsterdam/Philadelphia: John Benjamins Publishing Company. doi:10.1075/pbns.72

Martiny, T. 1996. "Forms of Address in French and Dutch: A Sociopragmatic Approach." Language Sciences 18 (3-4): 365-375.

Masliyah, Sadok. 1998. "Abu and umm in the Iraqi Dialect." Journal of Semitic Studies 43 (1): 113-129. doi:10.1093/jss/43.1.113

Myers Scotton, Carol, and Zhu Wanjin. 1983. "Tóngzhì in China: Language Change and its Conversational Consequences." Language in Society 12 (4): 477-494. doi: $10.1017 /$ So047404500010204

Myers Scotton, Carol, and Zhu Wanjin. 1984. “The Multiple Meanings of shī.fu, a Language Change in Progress.” Anthropological Linguistics 26 (3): 326-344.

Pajusalu, Renate, Virve-Anneli Vihman, Birute Klaas, and Karl Pajusalu. 2010. "Forms of Address across Languages: Formal and Informal Second Person Pronoun Usage among Estonia's Linguistic Communities.” Intercultural Pragmatics 7 (1): 75-101. doi:10.1515/iprg.2010.004

Parkinson, Dilworth B. 1985. Constructing the Social Context of Communication: Terms of Address in Egyptian Arabic. Berlin/New York/Amsterdam: Mouton de Gruyter.

Peipei, Ren. 2007. "Sociolinguistic Study on the Term of Address 'meinü' in Present-Day China." Canadian Social Science 3 (6): 101-106.

Potter, Terrence M. 1995. "Moroccan Terms of Address in the Film Dmu'al-Nadem (Tears of Regret)." The Georgetown Journal of Languages and Linguistics 3 (2-4): 218-226.

Rosch, Eleanor. 1978. "Principles of Categorization.” In Cognition and Categorization, ed. by Eleanor Rosch, and Barbara B. Lloyd, 27-48. Hillsdale, New Jersey: Lawrence Erlbaum Associates.

Romaine, Suzanne. 1994. Language in Society: An Introduction to Sociolinguistics. Oxford: Oxford University Press.

Salami, L. Oladipo. 2004. "Deference and Subordination: Gender Roles and other Variables in Addressing and Referring to Husbands by Yoruba Women." Linguistik online 21: 65-80.

Slobin, Dan I. 1963. "Some Aspects of the Use of Pronouns of Address in Yiddish." Word 19 (2): 193-202. doi:10.1080/00437956.1963.11659794

Thomas, Jenny A. 1995. Meaning in Interaction: An Introduction to Pragmatics. London/New York: Longman.

Trudgill, Peter. 1983. Sociolinguistics: An Introduction to Language and Society. Harmondsworth: Penguin Books.

Wardhaugh, Ronald. 1986. An Introduction to Sociolinguistics. Oxford: Basil Blackwell.

Wong, Andrew D. 2005. “The Reappropriation of Tongzhi.” Language in Society 34 (5): 763-793. doi: $10.1017 /$ So047404505050281 
Yassin, M. Aziz F. 1977. "Kinship Terms in Kuwaiti Arabic.” Anthropological Linguistics 19 (3): $126-132$.

Yoon, Kyung-Joo. 2004. "Not just Words: Korean Social Models and the Use of Honorifics." Intercultural Pragmatics 1 (2): 189-210. doi:10.1515/iprg.2004.1.2.189

Zhucheng, Ju. 1991. "The 'Depreciation' and 'Appreciation' of some Term of Address in China." Language in Society 20 (3): 387-390. doi:10.1017/So047404500016547

\section{Authors' addresses}

\section{Sami Ben Salamh}

Department of English Language and Translation

College of Languages and translation, King Saud University

P.O. Box: 87907

Riyadh 11652

Kingdom of Saudi Arabia

bensalamh@hotmail.com

Zouheir Maalej

Department of English Language and Translation

College of Languages and Translation

King Saud University

P.O. Box 87907

Riyadh 11652

Kingdom of Saudi Arabia

zmaalej@ksu.edu.sa

Mohammed Alghbban

Department of Modern Languages and Translation College of Languages and Translation King Saud University

P.O. Box 87907

Riyadh 11652

Kingdom of Saudi Arabia

alghbban@gmail.com 
